Supporting Information for

\title{
In situ Crumpling Gold Nanosheets into Spherical Three- dimensional Architecture: Probing the Aggregation-Induced Enhancement in Photothermal Properties
}

Xiaowei Fu, ${ }^{\text {a† }}$ Juan Tan, ${ }^{\text {b† }}$ Yanyun Ma, ${ }^{\mathrm{c}} \mathrm{Na}$ Zhao, ${ }^{\mathrm{a}}$ Yuhan Kong, ${ }^{\mathrm{a}}$ Feng Liu, ${ }^{\mathrm{d}}$ Yiqun Zheng, ${ }^{\mathrm{a}}{ }^{\mathrm{Y}} \mathrm{Y}$ Wang, ${ }^{\text {,* }}$ and Maochang Liu ${ }^{\mathrm{d}}$

a School of Chemistry, Chemical Engineering, and Materials, Jining University, Qufu, Shandong 273115, P. R. China

b Chongqing Key Laboratory of Green Synthesis and Applications, College of Chemistry, Chongqing Normal University, Chongqing 401331, P. R. China

${ }^{\mathrm{c}}$ Institute of Functional Nano \& Soft Materials (FUNSOM), Jiangsu Key Laboratory for CarbonBased Functional Materials \& Devices, Soochow University, Suzhou, Jiangsu 215123, P. R. China d International Research Center for Renewable Energy, National Key Laboratory of Multiphase Flow in Power Engineering, Xi'an Jiaotong University, Xi'an, Shaanxi 710049, China

$\dagger$ These two authors contribute equally to this work.

* Corresponding authors: Prof. Dr. Y. Zheng, E-mail: whzyq@163.com; Prof. Dr. Yi Wang, Email: ywang@cqnu.edu.cn

Number of Figures: 11

Number of Pages: 12

Number of Tables: 0 


\section{Table of Content}

Figure S1. Histogram showing the size distribution of Au NCPBs as displayed in Figure 2.

Figure S2. SEM images of Au NCPBs obtained via the standard procedure, except for using different amounts of OTAC.

Figure S3. Histogram showing the size distribution of Au NCPBs as displayed in Figure S2.

Figure S4. UV-vis extinction spectroscopy of Au NCPBs as shown in Figure S2.

Figure S5. UV-vis extinction spectroscopy of Au products as shown in Figure 3.

Figure S6. SEM images of Au products obtained via the standard procedure, except for using different amounts of glutathione.

Figure S7. SEM images of Au products obtained via the standard procedure, except the sulfuric additive was replaced by a) $\mathrm{Na}_{2} \mathrm{SO}_{4}$, b) $\mathrm{Na}_{2} \mathrm{SO}_{3}$, and c) $\mathrm{Na}_{2} \mathrm{~S}$ at the same amount.

Figure S8. SEM images of Au products obtained via the standard procedure, except for using different amounts of $\mathrm{Na}_{2} \mathrm{~S}_{2} \mathrm{O}_{3}$.

Figure S9. SEM images of Au products obtained via the standard procedure, except for under different reaction temperatures.

Figure S10. CV traces of Au flat nanoplates (see Figure S2a) and Au NCPBs.

Figure S11. SEM images of Au nanocrystals after 808-nm laser irritation for photothermal conversion measurement. 


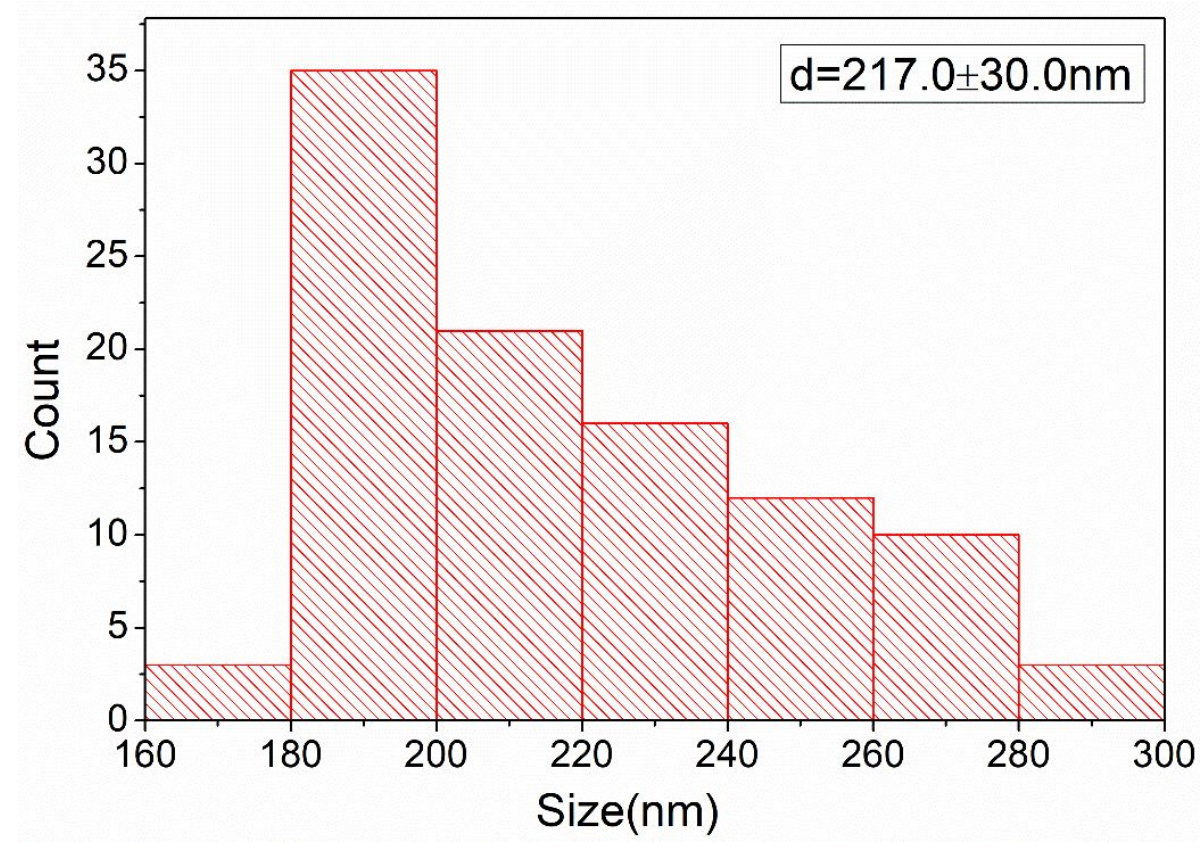

Figure S1. Histogram showing the size distribution of Au NCPBs as displayed in Figure 2. 


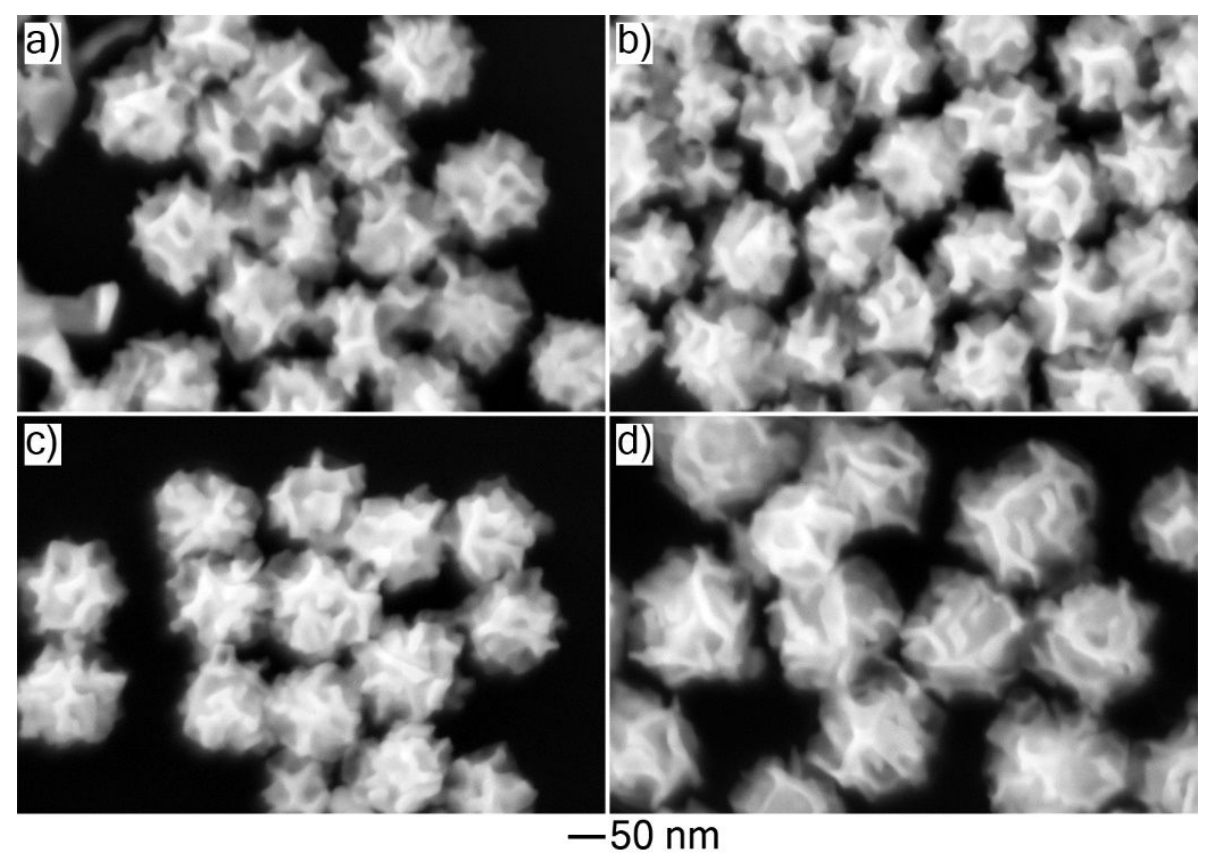

Figure S2. SEM images of Au NCPBs obtained via the standard procedure, except that the amount of OTAC was tuned to a) $100 \mu \mathrm{mol}$, b) $200 \mu \mathrm{mol}$, c) $400 \mu \mathrm{mol}$, and d) $1000 \mu \mathrm{mol}$, respectively. 

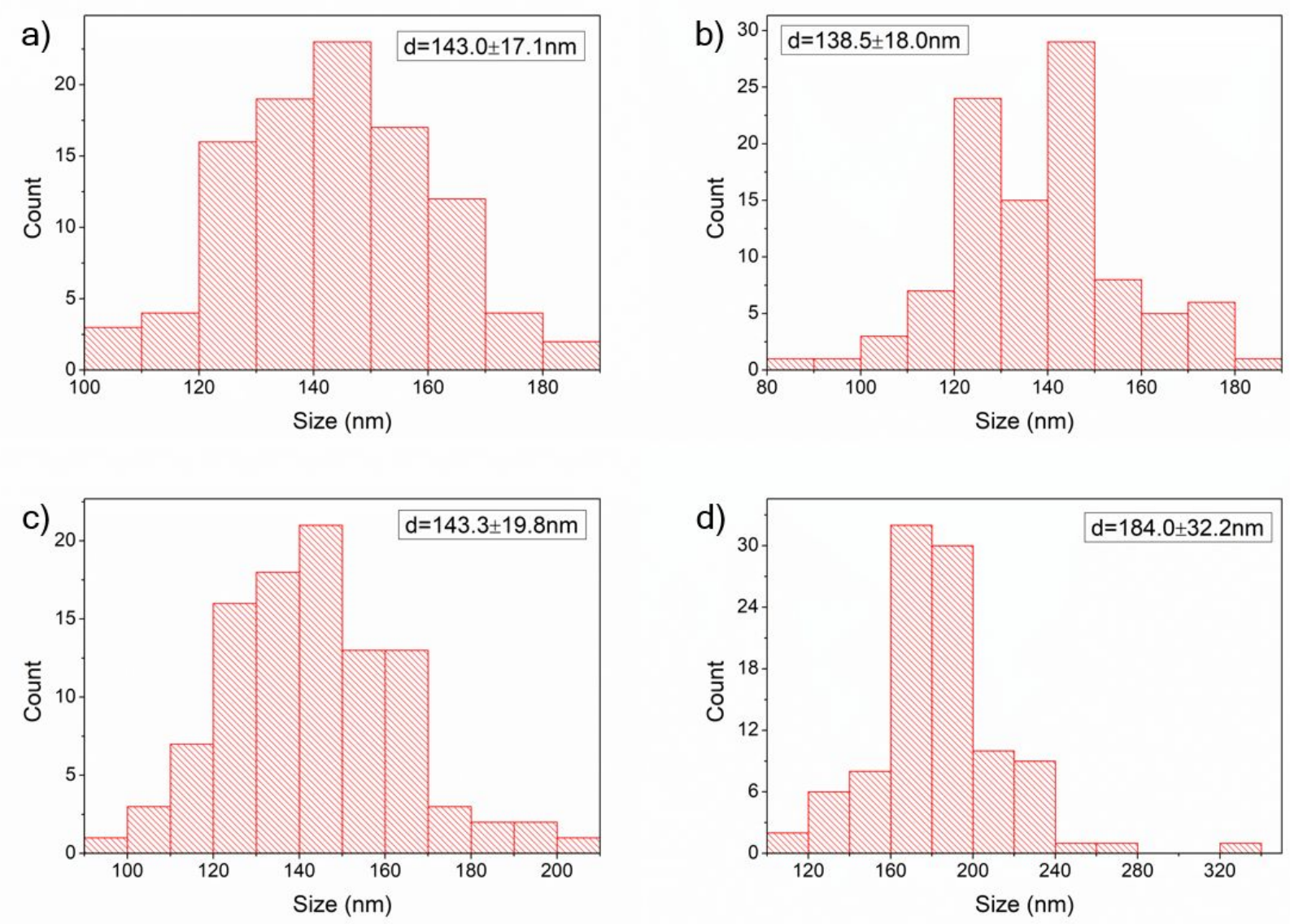

Figure S3. Histogram showing the size distribution of Au NCPBs as displayed in Figure S2: a) Figure S2a; b) Figure S2b; c) Figure S2c; d) Figure S2d, respectively. 

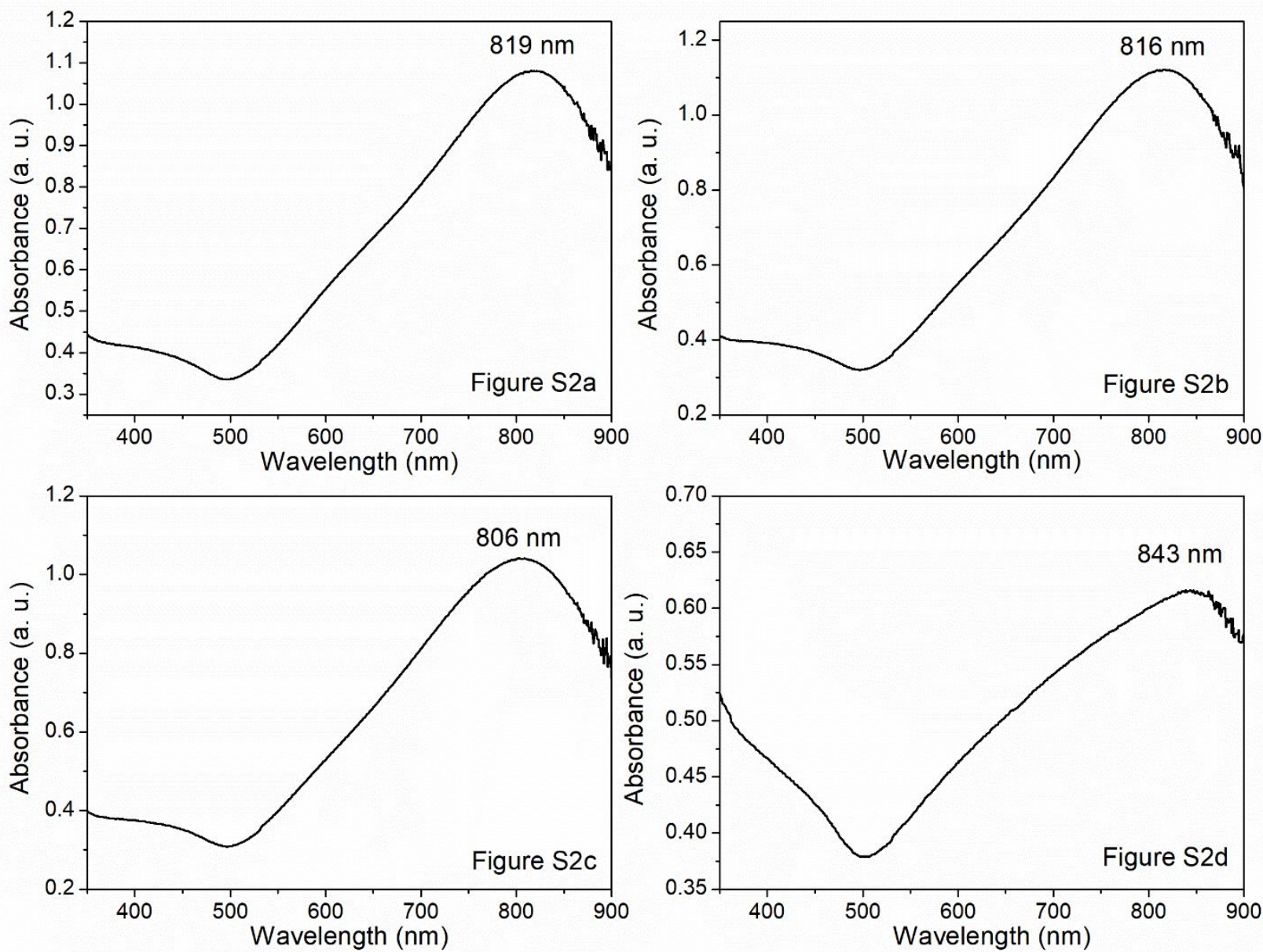

Figure S4. UV-vis extinction spectra of Au NCPBs as shown in Figure S2. 

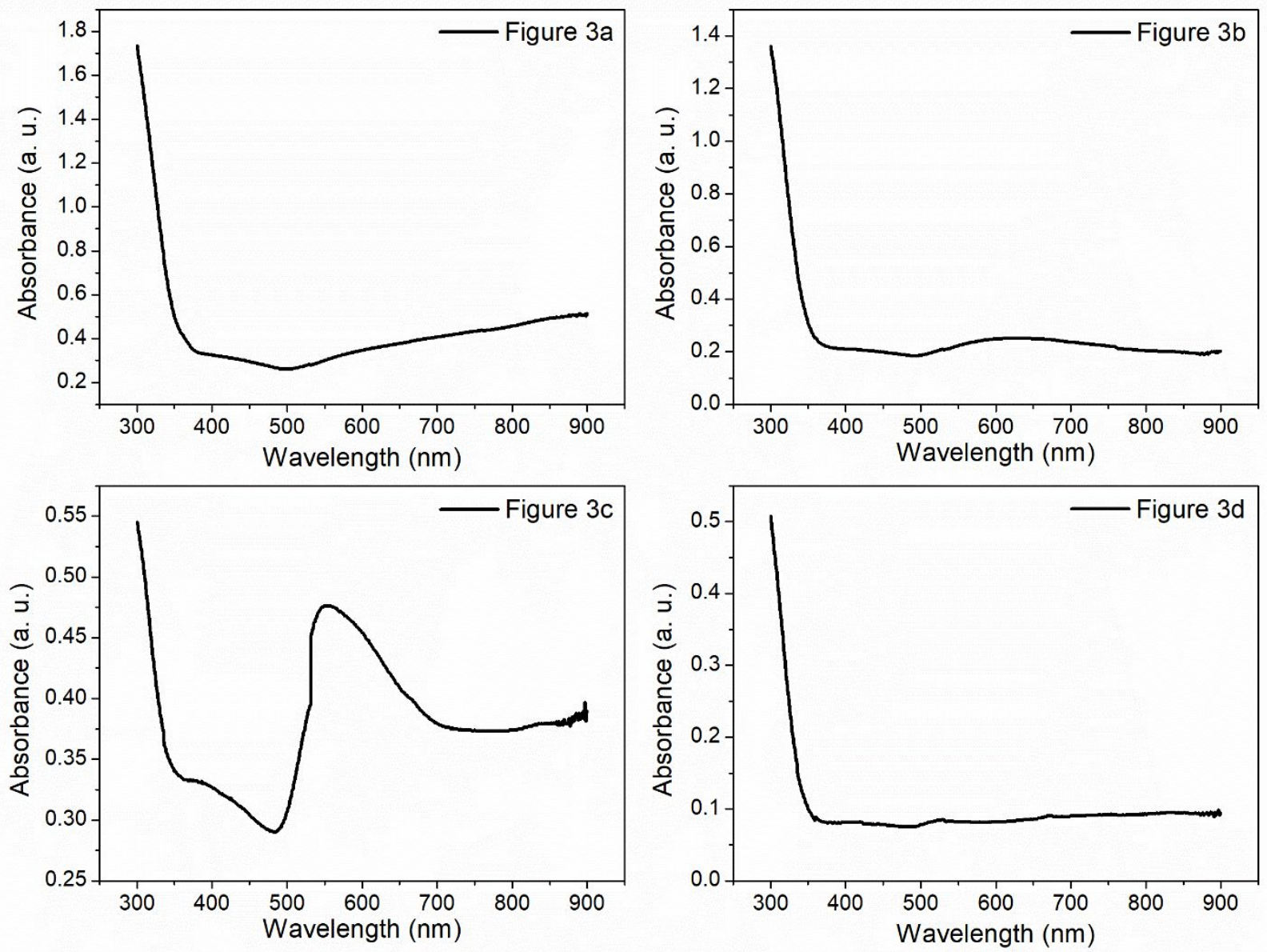

Figure S5. UV-vis extinction spectra of Au products as shown in Figure 3. 

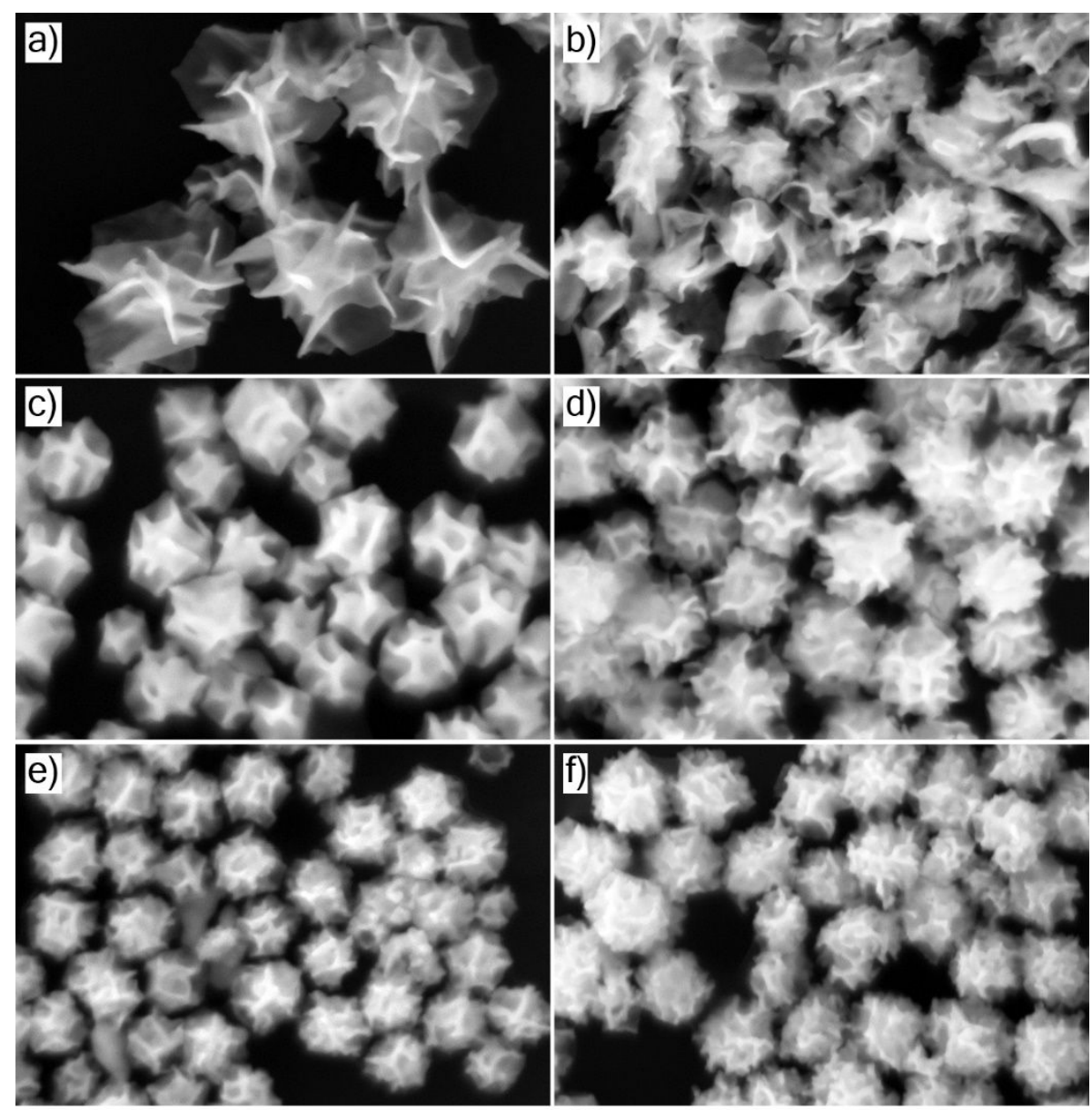

$-100 \mathrm{~nm}$

Figure S6. SEM images of Au products obtained via the standard procedure, except the volume of glutathione ( $0.5 \mathrm{mM})$ was varied to a) 0 , b) $10 \mu \mathrm{L}$, c) $20 \mu \mathrm{L}$, d) $50 \mu \mathrm{L}$, e) $100 \mu \mathrm{L}$, f) $200 \mu \mathrm{L}$, respectively. 

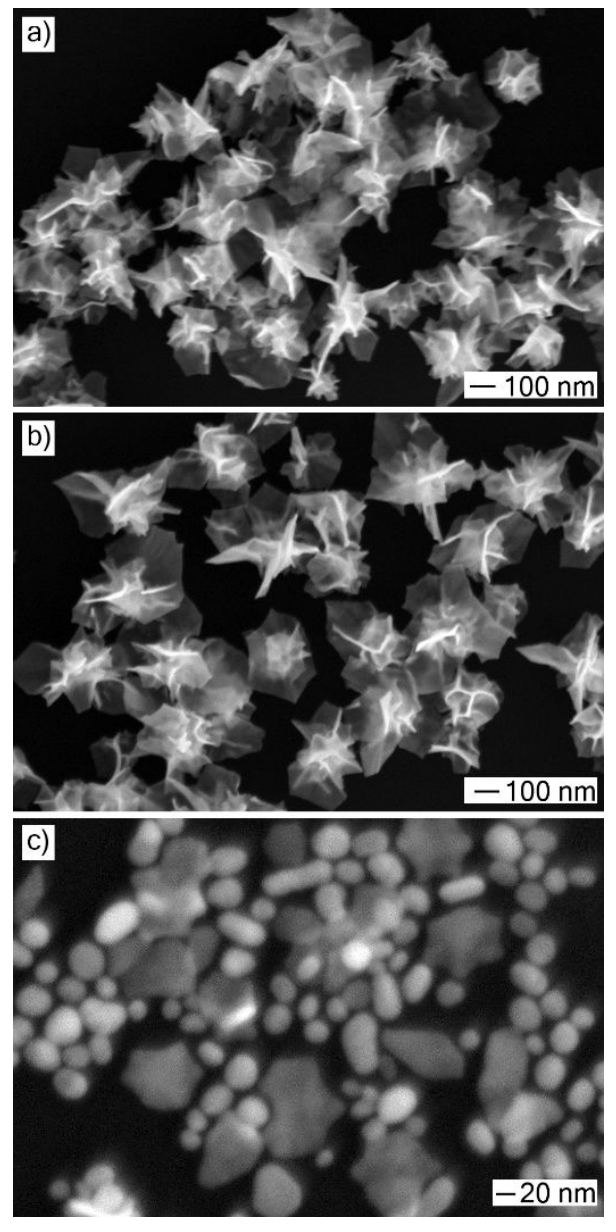

Figure S7. SEM images of Au products obtained via the standard procedure, except the sulfuric additive glutathione was replaced by a) $\mathrm{Na}_{2} \mathrm{SO}_{4}$, b) $\mathrm{Na}_{2} \mathrm{SO}_{3}$, and c) $\mathrm{Na}_{2} \mathrm{~S}$ at the same amount. 

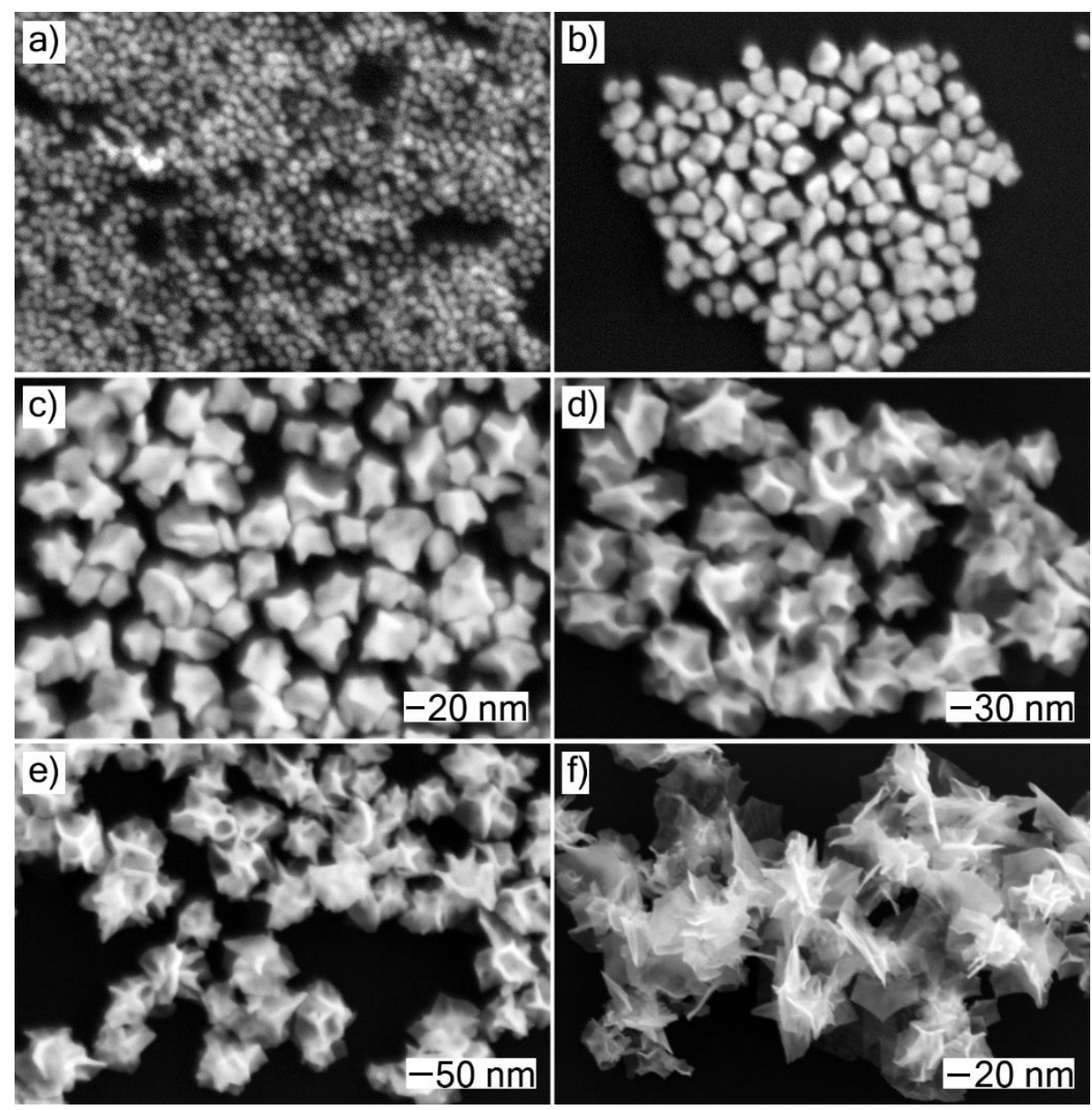

Figure S8. SEM images of Au products obtained via the standard procedure, except the sulfuric additive was replaced by $\mathrm{Na}_{2} \mathrm{~S}_{2} \mathrm{O}_{3}(0.5 \mathrm{mM})$ and the volume was varied to a) 200 , b) $\left.100 \mu \mathrm{L}, \mathrm{c}\right)$ $50 \mu \mathrm{L}$, d) $20 \mu \mathrm{L}$, e) $10 \mu \mathrm{L}, \mathrm{f}) 0 \mu \mathrm{L}$, respectively. 


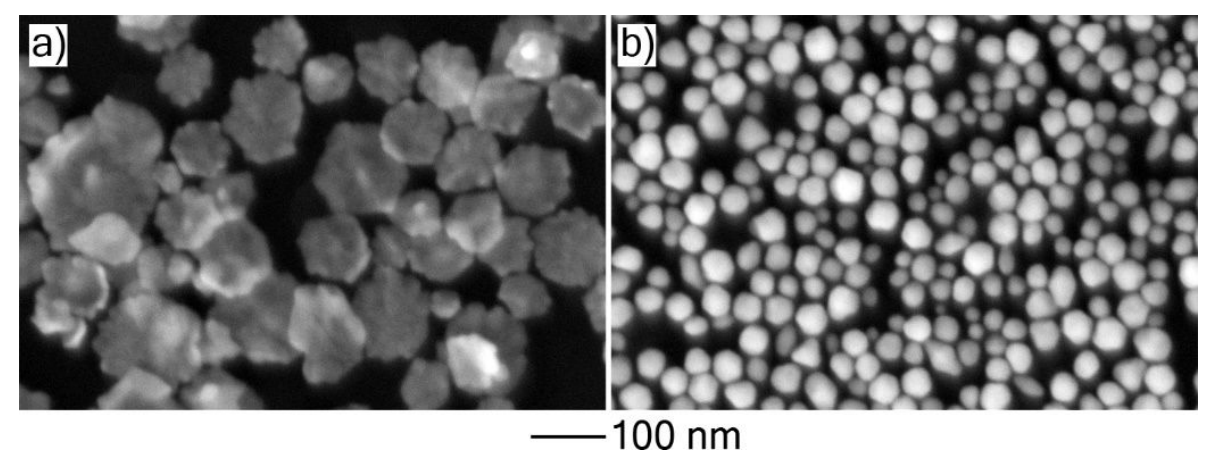

Figure S9. Effect of reaction temperature on product morphology. SEM images of Au products obtained via the standard procedure, except that the reaction temperature was varied to a) approaching $0{ }^{\circ} \mathrm{C}$ and b) $60^{\circ} \mathrm{C}$, respectively. 


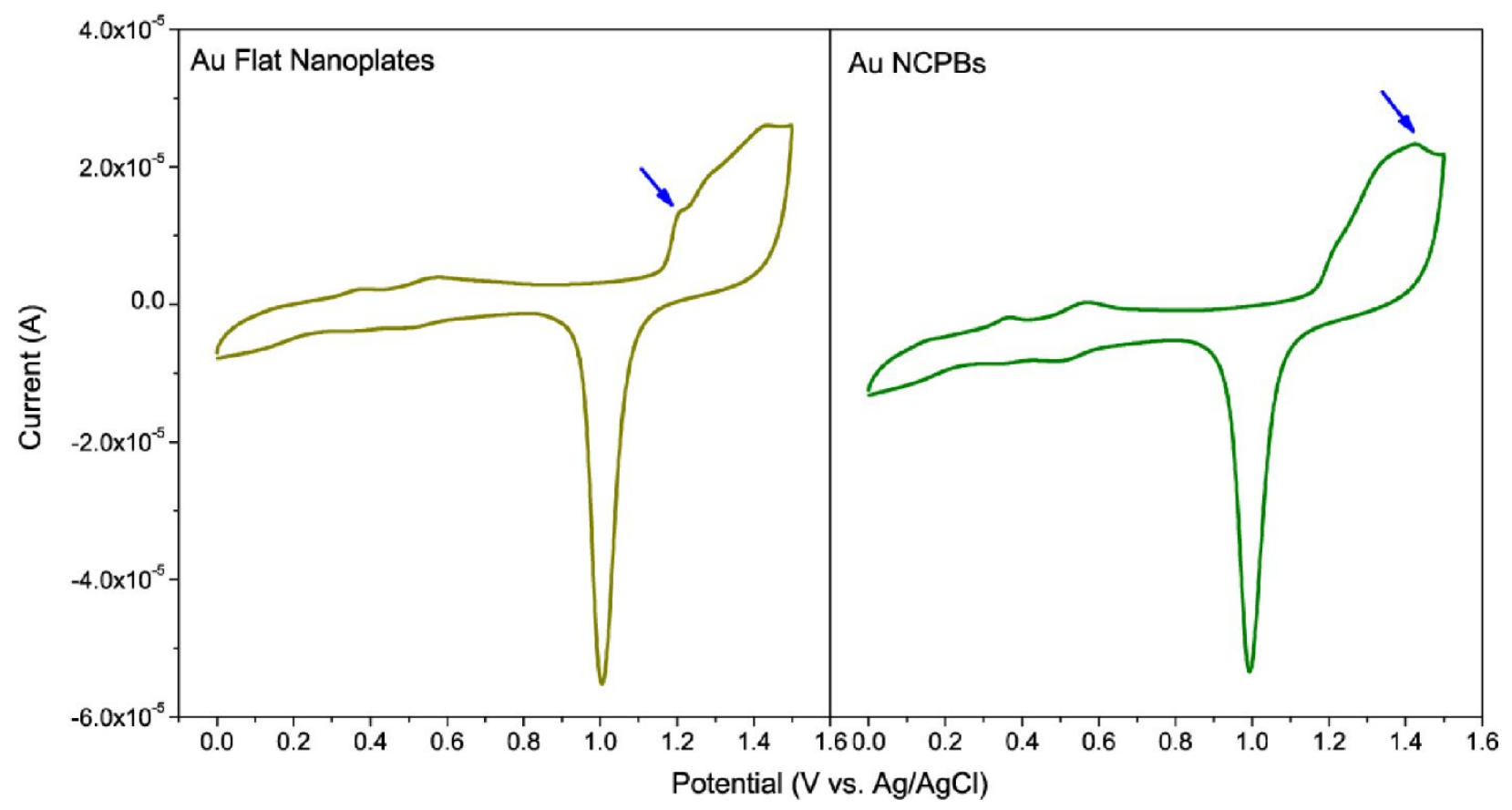

Figure S10. CV traces of Au flat nanoplates (see Figure S2a) and Au NCPBs. Condition: electrolyte: $0.1 \mathrm{M} \mathrm{H} 2 \mathrm{SO} 4$; scan rate: $20 \mathrm{mV} / \mathrm{s}$. 

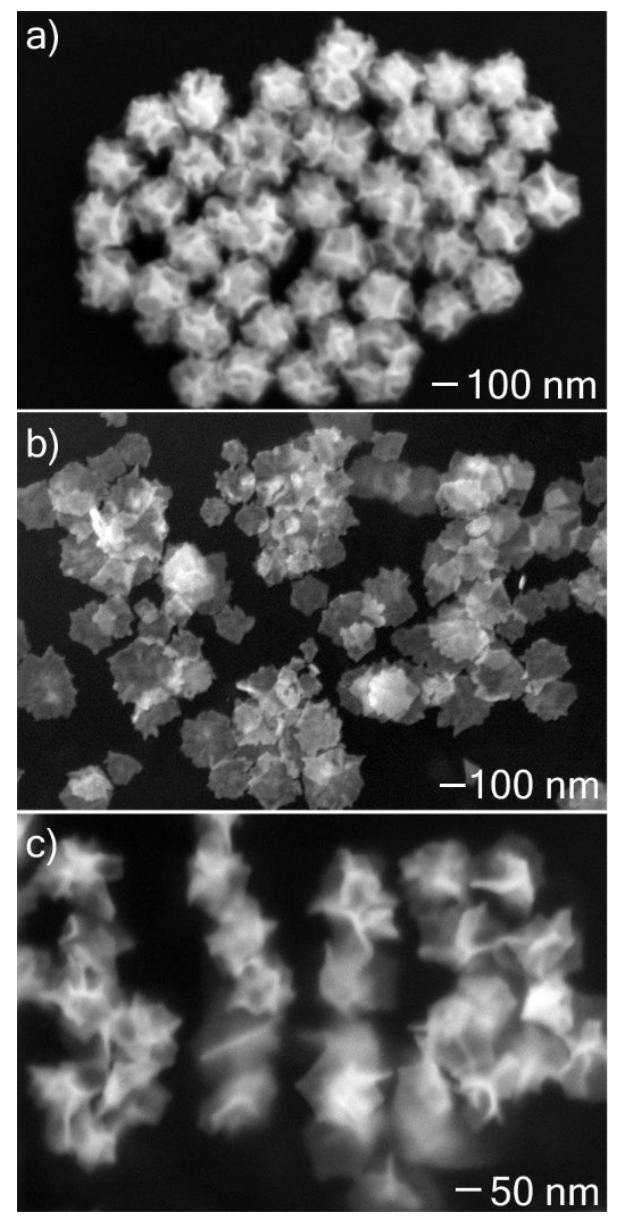

Figure S11. SEM images of a) NCPBs, b) FNSs, and c) WNSs, after 808-nm laser irritation during photothermal conversion measurement. 